\title{
SERVICE QUALITY RADAR MAP AND TWO-STAGE SERVICE QUALITY SCORE
}

Kee-Kuo Chen

Department of Shipping and Transportation Management, National Taiwan Ocean University, 2, Pei-Ning Road, Keelung 202, Taiwan, R.O.C., kkchen@mail.ntou.edu.tw

Ding-Hsun Hsiao

Department of Shipping and Transportation Management, National Taiwan Ocean University, 2, Pei-Ning Road, Keelung 202, Taiwan, R.O.C.

Cheng-Hung Arthur Hsieh

Department of Shipping and Transportation Management, National Taiwan Ocean University, 2, Pei-Ning Road, Keelung 202, Taiwan, R.O.C.

Follow this and additional works at: https://jmstt.ntou.edu.tw/journal

Part of the Business Commons, and the Transportation Engineering Commons

\section{Recommended Citation}

Chen, Kee-Kuo; Hsiao, Ding-Hsun; and Hsieh, Cheng-Hung Arthur (2008) "SERVICE QUALITY RADAR MAP AND TWOSTAGE SERVICE QUALITY SCORE," Journal of Marine Science and Technology: Vol. 16: Iss. 2, Article 4.

DOI: $10.51400 / 2709-6998.2022$

Available at: https://jmstt.ntou.edu.tw/journal/vol16/iss2/4

This Research Article is brought to you for free and open access by Journal of Marine Science and Technology. It has been accepted for inclusion in Journal of Marine Science and Technology by an authorized editor of Journal of Marine Science and Technology. 


\title{
SERVICE QUALITY RADAR MAP AND TWO-STAGE SERVICE QUALITY SCORE
}

\author{
Kee-Kuo Chen*, Ding-Hsun Hsiao*, and Cheng-Hung Arthur Hsieh*
}

Key words: importance-performance matrix, service quality performance zone, second stochastic dominance criterion, SERVQUAL.

\begin{abstract}
In an attempt to portray all information released from the service quality studies the service quality radar map (SQRM), is designed in this paper firstly and a generalized service quality score (GSQS) follows. GSQS is defined by way of the weighted average of differences between relative frequencies of customers' performance perception and performance expectation, thus can avoid the problems involved in the gap-based SERVQUAL scale and caused by skewed distributions. A special case of GSQS, the stochastic dominance service quality score (SDSQS) whose ideal come from the second stochastic dominance criterion is used to illustrate how a standardized score can be constructed to meet the required condition of SQRM. After that the two-stage service quality score (TSQS) is proposed. It is believed that SQRM with TSQS will make a contribution to exhibit the overall information of service quality delivered by a company---both academically and practically.
\end{abstract}

\section{INTRODUCTION}

Depicting service quality research findings graphically is a powerful way to communicate research information. However, a challenge still faced by researchers and practitioners is how to convert a complex set of data into single graph that can be comprehended easily by executives, managers or other persons who will make decisions based on their research of service quality. A simple way of tracking service performance that shows the scores for service reliability which is one of service factors have been done by Sivadas [42]. The zones of tolerance charts (Berry, et al. [4]) can show the information of dimensionality of service attributes only. The Importance-performance matrix (IPM) developed by Martilla and James [25] is such a technique that is extensively used in marketing research. In attempting to improve the function of IPM, Lambert and Sharma [21] and Lambert and Stock [22] display almost the same information as that in the Performance

Paper submitted 02/27/07; accepted 03/17/07. Author for correspondence: Kee-Kuo Chen (e-mail: kkchen@mail.ntou.edu.tw).

*Department of Shipping and Transportation Management, National Taiwan Ocean University, 2, Pei-Ning Road, Keelung 202, Taiwan, R.O.C.
Evaluation Matrix (PEM). Following them, Hung, et al. [17] proposes the service quality performance zone (SQPZ) in an attempt to modify the PEM. However, the word 'performance' used in IPM, PEM, and SQPZ usually refers to the customer satisfaction and the characteristics of service quality was ignored by these methods.

Except the importance and performance of each attribute, the performance of dimensionality of attributes becomes important information of service quality delivered by a company since Parasuraman, et al. [32] and Parasuraman, et al. [33, 34] abstracted 5 dimensions of service quality from 22 (service) attributes of SERVQUAL. The service quality score in SERVQUAL is defined as the difference of customer perceptions-minus-expectations (P-E) of attributes and contributes to the basis for a better understanding of the determinants of customer perceived service quality. Although there were scholars holding different views toward the 5 dimensions of service quality (Babakus and Boller [1]; Babakus and Mangold [2]; Brady, et al. [6]; Brown, et al. [7]; Cronin and Taylor [11, 12]; Hurley and Estelami [18]; Llosa, et al. [24], Oliver [30]; Peter, et al. [37]), all of them recognize the importance of dimensionality in the evaluation of service quality. None of IPM, PEM, and SQPZ are, however, able to reveal the information of the performance of the dimensionality of attributes and of the importance and performance of all attributes on a graph together.

Therefore it is believed that a graph that could exhibit overall information of the relative importance, performances as well as the dimensionality of service attributes can improve the efficiency of communication for the service quality between customers and firms and that it would be a powerful tool to managers by which the service quality delivered by firms could be assessed curiously.

In addition to the problem of exhibition of information, empirical studies show that the distributions of most measures of service quality or customer satisfaction are negatively skewed (Estelami and DeMaeyer [14]; Hurley and Estelami [18]; Parasuraman et al. [35]; Peterson and Wilson [38]). In particular, Peterson and Wilson [38] suggest that an average rating based on the arithmetic mean of the consumer responses is likely to be a poor measure of central tendency and also may not be the best indicator of service quality and satisfaction.

The first objective of this paper is to construct a service quality radar map (SQRM) which is to show the overall service quality profile delivered by an organization. The SQRM can display information pertaining to individual attributes, dimensions of attributes, and attributes as a whole provided by 


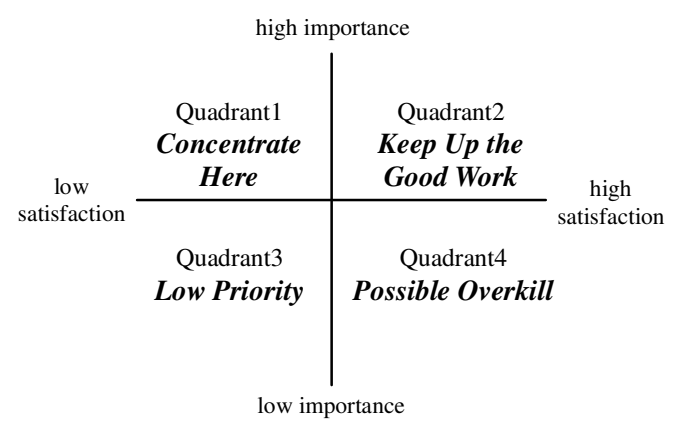

Fig. 1. Importance-performance analysis grid (presented by Martilla and James, 1977).

companies or markets simultaneously. The second objective is to propose a standardized index, the two-stage service quality score (TSQS), which can be used to score service qualities of attributes on SQRM. It is believed that SQRM with TSQS will make a contribution to exhibit the information of service quality---both academically and practically.

\section{IMPORTANCE-PERFORMANCE MATRIX (IPM), PERFORMANCE EVALUATION MATRIX (PEM) AND SERVICE QUALITY PERFORMANCE ZONE (SQPZ)}

The challenge faced by marketing researchers is to convert a complex set of data into a graph that can be comprehended easily by executives, managers or other persons who will make decisions from the research results of service quality. The IPM is the form that is most often used by service quality researchers. The IPM was developed by Martilla and James [25] and has been widely applied by researchers in many studies (Chen and Chang [10]; Lambert and Sharma [21]; Martin [26]; Zhang and Chow [50]).

The IPM identifies the relative importance of the attributes associated with a service or product and indicates the degree of performances simultaneously. The IPM is plotted graphically on a two-dimensional grid. Attribute importance is usually represented on the vertical axis from high to low, while, performance is shown on the horizontal axis from low to high. The resulting four quadrants are: concentrate here, keep up the good work, low priority, and possible overkill as shown in Fig. 1.

Lambert and Sharma [21] and Lambert and Stock [22] modified the four quadrants to a nine-cell box that is called the Performance Evaluation Matrix. PEM does not manifest as an increase in the functions of IPM substantially. Hung, et al. [17] have mentioned three shortcomings of PEM: (1) a lack of generalization and standardization, (2) incompleteness of improvement strategies, and (3) a lack of statistical inference, and proposed a service quality performance zone (SQPZ) which exhibits two standard indexes that are developed based on two parameters in beta distribution. One is the standard index of customer satisfaction and the other is the standard index of customer expectation. These authors also advocate using interval estimation of indices instead of point estimation of indicators of service quality in IPM and PEM; however, the result seems to have few improvements of the functions of these two traditional methods.

\section{SERVICE QUALITY RADAR MAP (SQRM)}

Parasuraman, et al. [32] and Parasuraman et al. [33, 34] abstracted 5 dimensions of service quality from 22 attributes of SERVQUAL. The authors made pioneering ventures to comprehend the construct of service quality and its determinants. Although there were scholars holding different views toward the 5 dimensions of service quality (Babakus and Boller [1]; Babakus and Mangold [2]; Brady, et al. [6]; Brown, et al. [7]; Cronin and Taylor [11, 12]; Hurley and Estelami [18]; Llosa, et al. [24], Oliver [30]; Peter, et al. [37]), all of them recognize the importance of dimensionality in the evaluation of service quality. This information about performance of each dimension of service attributes conducted by an organization is, however, not revealed in IPM, PEM and SQPZ. In addition, these three techniques are difficult to be used to compare service performances of two companies or compare service performances of a company to the market average. In an attempt to design the presentation of a company's overall service quality in a graph or of a comparison of service quality between 2 companies, a method of exhibition in which not only individual attribute and the dimensionality of all attributes, but also the profile of attributes as a whole will be demonstrated as follows.

Let $D$ be the number of dimensions of service quality abstracted from survey data by factor analysis, and specify names to each dimension, and let $\lambda_{d}$ be the eigenvalue corresponding to the dimension $d$, and $n_{d}$ be the number of attributes whose factor loading is statistically significant in the factor analysis included in the dimension, $\mathrm{d}=1,2, \ldots, D$; $\sum_{d=1}^{D} n_{d}=m^{\prime} \quad(<\mathrm{m}$, total number of attributes $)$ and $\sum_{d=1}^{D} \lambda_{d}=\lambda$. And define further,

$$
I S\left(j, j^{\prime}\right)=\sum_{i=1}^{k} a_{i}\left(p_{i j}^{I}-p_{i j^{\prime}}^{I}\right)
$$

where:

$a_{i}:(>0)$ the importance weight of scale level $i, i=1,2, \ldots, k$;

$p_{i j}^{I}$ : the relative frequency of importance scale $i$ of attribute $j$ in the sampling survey data, where scales are ranging from 1 , indicating the least important to $\mathrm{k}$, indicating the most important, $i=1,2, \ldots, k$;

$I S\left(j, j^{\prime}\right):$ an indicator of difference of relative importance perceived by surveyed respondents between attribute $j$ and $j^{\prime}, j, j^{\prime}=1,2, \ldots, m \quad$; and

$S S Q_{j}$ : a standardized service quality score of attribute $j,-1 \leq S S Q_{j} \leq 1$.

SQRM is then constructed according to the following steps: Step 1: Rank the relative importance of the attributes by using $I S\left(j, j^{\prime}\right)$ (ranging from 1, indicating the least importance to $\mathrm{m}$, indicating the most importance). We assume that none of the values of $I S\left(j, j^{\prime}\right)$ are equal; oth- 
erwise the ranks of the tied attributes are substituted by the average value of them;

Step 2: Fix a point as a center to draw two circles with radii of 1 and 2, respectively;

Step 3: Divide the small circle(with a radius of 1) into $D$ sectors according to the ratios of $\lambda_{d} / \lambda$, the length of the arc in every sector of the circle will thus be $2 \pi \times\left(\lambda_{d} / \lambda\right)$ and, $d=1,2, \ldots, D$; use two bold straight lines to connect the center of the circle with both ends of arcs in every sector, respectively. Label the name for each sector which corresponds to the dimension respectively, (refer to Fig. 2(a));

Step 4: Each sector is further divided into $n_{d}$ subsectors with equal angle, where $d=1,2 \ldots D$. We can divide each sector into $n_{d}$ subsectors with angles according to the ratios of its factor loading to the total significant factor loadings in a dimension. But this choice is not only tedious, but also meaningless because these factor loadings are usually closed.

Step 5: After dividing the area of dimension $d$ into $n_{d}$ subsectors with equal angles, connect the center of the circle with the midpoint of the arc in each subsector, extend the line to the circumference of the big circle and then label every midpoint of each subsector's arc of the small circle as 0 , the center point as -1 and the other end of the line as 1 . This line is thus defined as the $S S Q_{j}$ line and is labeled by its corresponding attribute number by the edge of the outside circle. The service quality prehistoric map (SQPM) is then obtained after completion of the above steps for every dimension as shown in Fig. 2(a).

Step 6: Mark the respective $S S Q_{j}$ for each attribute and connect $S S Q_{j}$ marks one by one with straight lines.

Step 7: Label its importance order ( ranked by $I S\left(j, j^{\prime}\right)$ ) for each attribute at an appropriate place to complete a SQ profile of the overall service quality.

For example, Fig. 2(a) is the service quality prehistoric map, SQPM, that was made on the basis of the result of factor analysis presented in Hurley and Estelami Table 2 ([18], p. 213). Hurley and Estelami divide 16 attributes into 3 dimensions of cleanliness of the facility, food quality and employee responsiveness. The eigenvalues of three dimensions are 7.85 , 1.55 and 1.06 , or equivalent to the proportions of $0.75,0.15$ and 0.10 , respectively. The circle then is divided into 3 sectors of arc-shaped area according to these proportions and the three sectors thus are labeled with their specific names, respectively. Since consisting of 8 attributes, the dimension of cleanliness of the facility is further divided into 8 equal subsectors. The arc midpoints of these subsectors are connected to the center of the circle with straight lines, respectively. Those lines are further extended out of the circle with a length of 1 and thus become their respective $S S Q_{j}$ lines for these 8 attributes. The other 2 dimensions are treated in the same way and the $S S Q_{j}$ lines for their respective attributes are produced. The picture produced looks like the radiant lines of a radar map, and called as service quality prehistoric map.

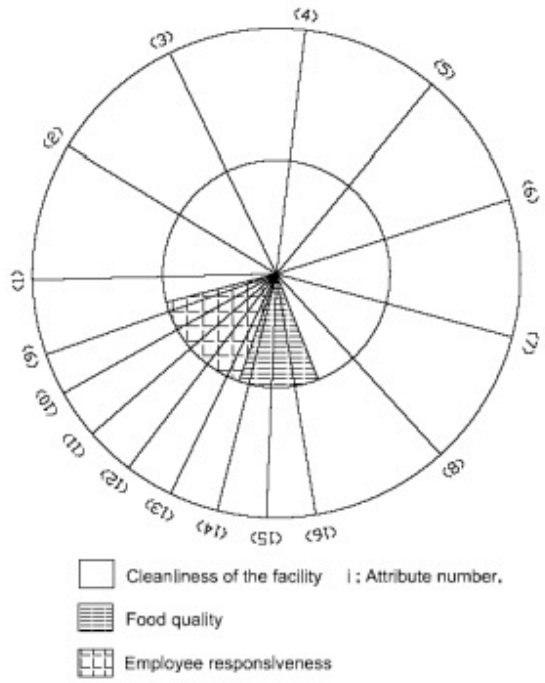

Figure 2(a) SQRM

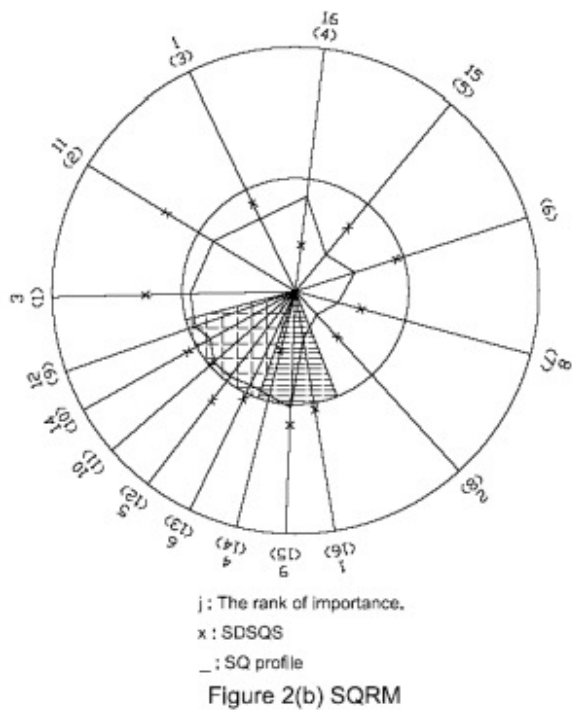

Suppose that the detail data studied by Hurley and Estelami data [18] was available. Then the $S S Q_{j}$ s could be calculated and the SQ profile of the company could be produced as shown in Fig. 2(b). The customers overall impression towards the service quality of this specific company is clearly displayed in this Figure. It can be easily inferred from the SQ profile that customers do not give high appreciation to the overall service quality provided by the company because the entire SQ profile is almost inside of the circle with a radius of 1 except the $S S Q_{j}$ mark of attribute 15 . In particular, as the most dominant dimension due to the coverage of three most importance attributes in this dimension, the service quality of the cleanliness of facility is lower because all the $S S Q_{j}$ s are less than 0 . Among the three dimensions, food quality seems to make slightly high service quality since the average $S S Q_{j}$ of this dimension is higher than that of the other two and also its $S S Q_{j} s$ are fairly even comparing to that of others. 
Suppose the points marked by crosses in the graph represent the attribute $S S Q_{j} s$ of this company's major competitor, then it can be asserted that the competitor's service quality is superior to the company's because all the competitor's $S S Q_{j} s$ of attributes are farther away from the center than that of the company except attributes 4, 9 and 14 whose importance ranks are 16, 12 and 4, respectively. Except attribute 14, the importance ranks of attributes 4 and 9 are 16 and 12, respectively, both are greater than average rank (11.5). This means that, compared to other attributes, attributes 4 and 9 are not so important in the customers' perception of service quality. Therefore, attribute 14 should be first considered if the competitor wants to improve the service quality.

Compared with IPM, PEM and SQPZ, the SQRM is more informative since more information relevant to decision-making is included in SQRM. In addition to the inclusion of the scores of service quality and importance ranks of all attributes, as IPM, PEM and SQPZ do, SQRM also discloses the features of dimensionality of service. The size of the area that each service dimension occupies can be obtained by calculating the ratio of the dimensional eigenvalue individually to the total of all eigenvalues and this size shows the relative importance of the dimension within the services delivered by a company or a market.

One of the important advantages of SQRM is that the shape and the size of the area of SQ profile can completely display the service quality of individual attribute, dimensions and the attributes as a whole in a single figure. This advantage contributes one of the most important academic and practical goals of marketing research of service. Although the concept of the radar map in a simple form has been used in the studies of financial management, but, to the best of authors' knowledge, the technique has not yet been used in marketing research.

Another advantage of the SQRM is that the standard of comparison used by this graph is clear. The comparison between attributes of service quality can be made by comparing the sizes of their $S S Q_{j}$, the farther away the $S S Q_{j}$ lies from the center, the higher service quality of the attribute. SQRM can assess the company's service performance of a particular dimension. This information is similar to that conveyed by the zones of tolerance charts (Berry, et al. [4]). The assessment of service quality on a particular dimension can be made by comparing the area of this dimension within the SQ profile with the sector area of the small circle occupied by this dimension. That the area of this dimension within the SQ profile is smaller than the sector area of the small circle occupied by this dimension indicates poor performance of this dimension conducted by the company, and vice versa.

In comparison to IPM, PEM and SQPZ, the presentation of relative importance of service dimensions is the unique feature of SQRM. The importance of the information of dimensional performances depends on what the type service quality measurement theory is. If the service quality measurement model is reflective, all attributes are caused by the same latent construct (dimension), dropping attributes does not change the latent construct's meaning as long as a construct retains a sufficient number of attributes (Hair, et al., [16]). This implies that the information of dimensionality in a service quality model is more important than that of individual attribute. Service quality model is a model of attitudes which should fit the reflective measurement model well (Bollen and Lennox, [5]). In this aspect SQRM is a better technique than other techniques mentioned above to exhibit the dimensionality information of service quality.

Moreover, the assessment of the overall service quality of a particular company can be made according to the size of area surrounded by its SQ profile, while, the one with larger area has a higher service quality. As long as the area surrounded by SQ profile of a company is smaller than the area of the small circle with radius of 1 (actually the area equals to $\pi$ ), the performance of service provided by the company is thus lower than the customer expectations toward the company.

Another important property of SQRM is that it makes easily to compare service qualities of an individual attribute or attributes as a whole among companies or markets. It is not difficult to image what a terrible mess for two or more sets of service quality scores belonging to different companies or markets to be laid on an IPM, PEM or SQPZ. Using the SQ profile, SQRM can display these sets of service quality scores distinctly as Fig. 2(b). The SQRM will enable the decision-makers to place all the information of the overall service quality of different companies or markets on the same radar map. Therefore, the decision-makers can proceed to compare either the difference in service quality delivered by different companies, or the difference in service quality in various timing delivered by the same company. This information, conveyed by SQRM with the importance ranks of attributes attached at the edged of SQRM, will make it easy for the decision makers to choose their service quality improvement strategies.

In summary, the differences of information contents revealed in SQRM, IPM, PEM, and SQPZ are listed in Table 1. The advantages of SQRM, compared to other techniques, are clearly shown in Table 1 because SQRM is the only technique that can reveal all relevant information of service quality. The requirement of a SSQ to be applied is not a stringent constraint. A method to calculate SSQ will be proposed in the following sections. The proposed method not only can be applied to SQRM, but also can avoid the problems caused by the P-E specification and caused by the skewed distributions of customer's perceived performances and expectations.

\section{STOCHASTIC DOMINANCE SERVICE QUALITY SCORE (SDSQS)}

P-E specification

The operationalization of the quality concept in empirical studies (Parasuraman, et al. [32, 33, 34]) suggests that perceived service quality can be conceptualized with the following P-E measurement model:

$$
S Q_{i}=\frac{1}{22} \sum_{j=1}^{22}\left(P_{i j}-E_{i j}\right)
$$


Table 1. Summary of comparison of service quality information exhibition techniques.

\begin{tabular}{|c|c|c|c|c|c|}
\hline \multicolumn{2}{|c|}{ Technique } & SQRM & IPM & PEM & SQPZ \\
\hline $\begin{array}{c}\text { Attributes } \\
\text { Information }\end{array}$ & Expectation & $\mathrm{X}^{*}$ & & & \\
\cline { 2 - 6 } & $\begin{array}{c}\text { (Perceived) } \\
\text { Performance } \\
\text { or } \\
\text { Satisfaction }\end{array}$ & $\mathrm{X}$ & $\mathrm{X}$ & $\mathrm{X}$ & $\mathrm{X}$ \\
\cline { 2 - 6 } & Importance & $\mathrm{X}$ & $\mathrm{X}$ & $\mathrm{X}$ & $\mathrm{X}$ \\
\cline { 2 - 6 } & Dimension & $\mathrm{X}$ & & & \\
\hline \multirow{2}{*}{$\begin{array}{c}\text { Standardized index } \\
\text { required }\end{array}$} & $\mathrm{X}$ & & & $\mathrm{X}$ \\
\hline
\end{tabular}

* $\mathrm{X}$ denotes the information being revealed.

Where:

$s Q_{i}=\mathrm{SERVQUAL}$ overall perceived quality of stimulus $i$.

$22=$ the number of attributes.

$P_{i j}=$ Performance perception of stimulus $i$ with respect to attribute $j$.

$E_{i j}=$ Service quality expectation for attribute $j$ that is the relevant norm for stimulus $i$.

The usefulness of the gap scores $s Q_{i}$ to represent service quality was questioned by some researchers. Some of criticisms has also acknowledged by Parasuraman et al. [36]. On the other hand, empirical studies show that the distributions of most measures of service quality or customer satisfaction are negatively skewed (Estelami and DeMaeyer [14]; Hurley and Estelami [18]; Parasuraman et al. [35]; Peterson and Wilson [38]). In particular, Peterson and Wilson [38] suggest that an average rating based on the arithmetic mean of the consumer responses is likely to be a poor measure of central tendency and also may not be the best indicator of service quality and satisfaction.

Because of the problems mentioned above and also because of a standardized service quality score required by the SQRM, a service quality specification that is called the generalized service quality score, hereinafter referred to as GSQS, is proposed.

Suppose that a survey instrument is asked for the respondents' expectation and perception of the actual level of service quality delivered by an organization with respect to $m$ attribute items on a $k$-point Likert scale where scales are ranging from 1 , indicating the least important to $\mathrm{k}$, indicating the most important, $i=1,2, \ldots, k$.

$G S Q S$ is defined by:

$$
\operatorname{GSQS}_{j}(\{w 1, w 2, \cdots w k\})=\sum_{i=1}^{k} w_{i}\left(p_{i j}^{E}-p_{i j}^{p}\right)
$$

where:

$\left\{w_{1}, w_{2}, \ldots, w_{k}\right\}=$ the weights set of rating scale set by the organization, where $w_{i}>w_{i^{\prime}}, \quad i<i^{\prime}$

$p_{i j}^{E}=$ the relative frequency of respondent's expectation rating scale $i$ of attribute $j$, and $\sum_{i=1}^{k} p_{i j}^{E}=1, j=1,2 \ldots m$ (total
Table 2. A hypothetical example for GSQS.

\begin{tabular}{|c|c|c|}
\hline & poor & good \\
\hline$p_{i}^{E}$ & 0.7 & 0.3 \\
\hline$p_{i}{ }_{i}$ & 0.2 & 0.8 \\
\hline$p_{i}^{E}-p_{i}{ }^{P}$ & 0.5 & -0.5 \\
\hline
\end{tabular}

number of attributes);

$p_{i j}^{p}=$ the relative frequency of respondent's perception (perceived performance) rating scale $i$ of attribute $j$, and $\sum_{i=1}^{k} p_{i j}^{p}=1 j=1,2 \ldots \mathrm{m}$.

$G S Q S_{j}>0$ means that the respondents' evaluation of the perceived performances of attribute $j$ is better than that of the expectations of this attribute in the organization's viewpoint, and vice versa. The required condition for the weights of GSQS can be demonstrated the following example. Suppose that the probability distributions of customers' expectations and perceptions of an attribute having only two rating scales of " $1=$ poor" and " $2=$ good" are tabulated in below.

It is obviously that the respondents' evaluation of the perceived performances is better than that of the expectations, and that the delivered service quality is evaluated as "good" is a reasonable tune. In this case GSOS will be positive only when the required condition, $w_{1}>w_{2}$, is satisfied.

The meaning of GSQS can be explained as follows. Since the expression $p_{i j}^{E}-p_{i j}^{P}$ is the difference between these two relative frequencies, therefore, from the prospect of management, customers' perceived service quality will be higher when $p_{i j}^{E}-p_{i j}^{P}$ becomes small for larger $i$. But when $i>i^{\prime}$, due to the correlation between the values of $p_{i j}^{E}-p_{i j}^{P}$ and $p_{i j}^{E}-p_{i j}^{P}$, if the value of is more negative, then the value of $p_{i^{\prime} j}^{E}-p_{i^{\prime} j}^{P}$ will be more positive. The weights reflect a decision-maker's preferences for different scales.

The specification of service quality given by GSQS is relatively more approximate to the original concept of disconfirmation presented by Oliver [28, 29] and Rosen, et al. [40] than the one given by Parasuraman et al. [33, 34]. In (3), the meaning of $p_{i j}^{E}-p_{i j}^{P}$ is considerable close to the Oliver's statement of "better-than-expected/ worse-than-expected" (Oliver $[28,29])$ and because $p_{i j}^{E}$ and $p_{i j}^{P}$ are the relative frequencies of customer expectation and customer perception (satisfaction) at scale $i$ of attribute $j$, respectively, where $i=1$, $2, \ldots, k ; j=1,2, \ldots, m$, the problem caused by subtracting customers' expectation scores $E_{i j}$ from their perception scores $P_{i j}$ (Cronin and Taylor [11, 12]; Teas [45]) can be avoided. Thus, the definition of GSQS avoiding to take the difference of the levels of customer expectation and of perception directly, it prevents GSQS from the criticism posited by Teas [45]. 
Table 3. Data comparison using second stochastic dominance criterion.

\begin{tabular}{|l|l|l|l|l|l|l|}
\hline & scale & 1 & 2 & 3 & 4 & 5 \\
\hline Group1 & E & 0.2 & 0.2 & 0.2 & 0.2 & 0.2 \\
\hline & $F^{E}$ & 0.2 & 0.4 & 0.6 & 0.8 & 1.0 \\
\hline & $\mathrm{P}$ & 0.1 & 0.2 & 0.4 & 0.2 & 0.1 \\
\hline & $F^{P}$ & 0.1 & 0.3 & 0.7 & 0.9 & 1.0 \\
\hline & $F^{E}-F^{P}$ & 0.1 & 0.1 & -0.1 & -0.1 & 0.0 \\
\hline & SDC & 0.1 & 0.2 & 0.1 & 0.0 & 0.0 \\
\hline Group2 & E & 0.0 & 0.2 & 0.3 & 0.3 & 0.2 \\
\hline & $F^{E}$ & 0.0 & 0.2 & 0.5 & 0.8 & 1.0 \\
\hline & $\mathrm{P}$ & 0.0 & 0.1 & 0.3 & 0.3 & 0.3 \\
\hline & $F^{P}$ & 0.0 & 0.1 & 0.4 & 0.7 & 1.0 \\
\hline & $F^{E}-F^{P}$ & 0.0 & 0.0 & 0.1 & 0.1 & 0.0 \\
\hline & SDC & 0.0 & 0.0 & 0.1 & 0.2 & 0.2 \\
\hline Group3 & E & 0.0 & 0.2 & 0.3 & 0.3 & 0.2 \\
\hline & $F^{E}$ & 0.0 & 0.2 & 0.5 & 0.8 & 1.0 \\
\hline & $\mathrm{P}$ & 0.01 & 0.0 & 0.0 & 0.0 & 0.99 \\
\hline & $F^{P}$ & 0.01 & 0.01 & 0.01 & 0.01 & 1.0 \\
\hline & $F^{E}-F^{P}$ & -0.01 & 0.19 & 0.49 & 0.79 & 0.0 \\
\hline & SDC & -0.01 & 0.18 & 0.67 & 1.46 & 1.46 \\
\hline
\end{tabular}

E: relative frequency of expectation

$P$ : relative frequency of performance

$F^{E}$ : cumulative distribution of $\mathrm{E}$

$F^{P}$ : cumulative distribution of $\mathrm{P}$

$S D C=\sum_{i=1}^{k^{\prime}}\left[F_{j}^{E}(i)-F_{j}^{P}(i)\right], \quad k^{\prime}=1,2,3,4,5$.

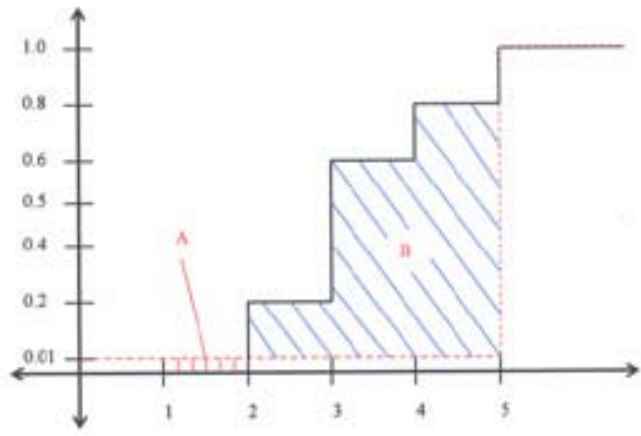

Fig. 3. Second stochastic dominance illustrated.

The definition of GSQS does not require any conditions for the distributions of customers' perceptions and expectations, the problem of negatively skewed distributions (Estelami and DeMaeyer [14]; Hurley and Estelami [18]) will not be involved in the GSQS. On the other hand, if we take $\left\{w_{1}, w_{2}, \ldots, w_{k}\right\}=\{1,2, \ldots, k\}$, then $\operatorname{GSQS}_{j}\left(\left\{w_{1}, w_{2}, \ldots w_{k}\right\}\right)=\bar{x}_{j, P}-\bar{x}_{j, E}$, where $\bar{x}_{j, P}$ and $\bar{x}_{j, E}$ are the average ratings of respondents' perceived performance and the average rating of respondents' expectation, respectively. Thus, the difference of two averages of sample data usually used by current empirical studies is a special case of GSQS, notwithstanding the concept of GSQS specification is not the same as the sample mean whose weights are referred to the relative frequencies on the locations; but, in (3), the relative frequencies are not treated as the set of $G S Q S$ weights

When $w_{i}=k-(i-1), i=1,2, \ldots, k$; then

$$
\begin{aligned}
\operatorname{GSQS}_{j}\left(\left\{w_{1}, w_{2}, \cdots w_{k}\right\}\right) & =\sum_{i=1}^{k}[k-(i-1)]\left(p_{i j}^{E}-p_{i j}^{p}\right) \\
& =\sum_{i=1}^{k}\left[F_{j}^{E}(i)-F_{j} P_{j}(i)\right]
\end{aligned}
$$

in which, $F_{j}^{X}(i)=\sum_{l=1}^{i} p_{l j}^{X}, i=1,2, \ldots, k$, and is the cumulative distribution function of random variable X. In (4), $\sum_{i=1}^{k}\left[F_{j}^{E}(i)-F_{j}^{P}(i)\right]$ at the right-hand side is the last value of the second order stochastic dominance criterion (SDC; Rothschild and Stiglitz [41]).

The definition of the second order stochastic dominance criterion is as follows. Let $F_{A}(x)$ and $F_{B}(x)$, respectively, be two cumulative distribution functions for two random variables $\mathrm{A}$ and $\mathrm{B}$ in $[a, b]$. When the second order of $F_{A}(x)$ stochastically dominates $F_{B}(x)$, it is marked in $F_{A} \succ F_{B}$, if and only if for any $x$ :

$$
\int_{-\infty}^{x}\left[F_{B}(t)-F_{A}(t)\right] d t \geq 0
$$

with strict inequality for some meaningful intervals of values of $t$. When random variables are of discrete type with possible values $i=1,2, \ldots, k$; equation ( 5 ) can be written as:

$$
\sum_{i=1}^{j}\left[F_{B}(i)-F_{A}(i)\right] \geq 0, \quad \forall j=1,2, \ldots, k .
$$

Since its introduction in 1970 by Rothschild and Stiglitz, the second order stochastic dominance criterion has been applied to compare the returns of financial assets (Whitmore [47]; Porter, et al. [39]; Bawa [3]; Levy and Kroll [23]; Vickson and Altman [46]; Kira and Ziemba [19]). To the authors' knowledge, this criterion has not been employed in other field.

By a theorem (Laffont [20]) that $F_{A} \succ F_{B}$ if and only if $E_{A} U(X) \geq E_{B U}(X)$ for all nondecreasing and concave function $U$, this implies that SDC will be preferred by all risk-averse decision makers, and also notice that when $U$ is taking as the identity function, SDC becomes the means-difference criterion. SDC is a method to compare distributions directly. Another advantage of SDC is that it can be used for comparing all kinds of probability distributions, not only considering means, medians and percentiles, etc. but also taking into account of the degree of dispersion of the distributions (Rothschild and Stiglitz [41], p.237). Therefore, SDC can provide more information than those statistics discussed by Hurley and Estelami [18].

However, it may be too conservative to use SDC as the criterion to examine the service quality. In Table 3, there are 3 groups of hypothetical survey data using a 5-point Likert-type scale, where scale 1 represents the lowest level and scale 5 the highest. 
The relative frequency of customers' expectations for the data in group 1 is uniform distribution, the customers' perceived performances data is unimode with symmetrical distribution, and all values in column SDC are greater than or equal to 0 while the former three values greater than 0 . As such, the result of comparison made in the second order stochastic dominance is therefore $F^{P} \succ F^{E}$. For those risk-averse decision makers who pay more attention to lower level than to higher level, it is a reasonable result. The two distributions of relative frequencies in group 2 show that customers' perceived performances is better than expected level, because $\left[1-F^{P}(i)\right] \geq\left[1-F^{E}(i)\right] i=1,2, \ldots, 5$. The five values in column SDC are all greater than or equal to 0 and show the result of $F^{P} \succ F^{E}$. This is again a reasonable result and shows higher service quality.

The data of group 3 shows the same customers' expectations distribution as that of group 2, but the distribution of customers' perceived performances of this group almost focuses on the level 5 totally, in fact, the relative frequency at level 5 is 0.99 . Comparing the data sets of group 2 and group 3, it is believed that the service quality of group 3 will be preferred to that of group 2 by all decision makers except those with extreme risk aversion. But the fact that some of the five values in column SDC are positive and some negative, and it can not be judged by SDC as which one is superior to the other.

Now we simplify SDC to focus only on the value, $\sum_{i=1}^{k}\left[F_{j}^{E}(i)-F_{j}^{P}(i)\right]$, the last value of SDC. Refer to Table 3, $\sum_{i=1}^{k}\left[F_{j}^{E}(i)-F_{j}^{P}(i)\right]$ are shown in the last row of column SDC, it is 1.46 at Group 3 and greater than 0.2 at Group 2. The result is more accepted than that made from judgment of SDC.

The value, $\sum_{i=1}^{k}\left[F_{j}^{E}(i)-F_{j}^{P}(i)\right]$, can be interpreted geometrically by the difference between areas A and B in Fig. 5, that is, $\sum_{i=1}^{k}\left[F_{j}^{E}(i)-F_{j}^{P}(i)\right]=($ area B)$)($ area A). Positive SDC at a level means that the cumulative relative frequency of customer expectations is still greater than that of customer perceived performances at that level. It is equivalently means that the cumulative relative frequency of customer expectations from level 5 to that level is less than that of the cumulative relative frequency of customer perceived performances from level 5 to that level, thus the service quality of this attribute should be considered as good.

Define

$$
\operatorname{SDSQS}_{j}=\frac{1}{k-1} \sum_{i=1}^{k}\left[F_{j}^{E}(i)-F_{j}^{P}(i)\right], j=1,2, \ldots, m
$$

Proposition 1. If $F_{j}^{P} \succ F_{j}^{E}$, then $\operatorname{SDSQS}{ }_{j} \geq 0$.

Proof: By equation ( $5^{\prime}$ ).

Proposition $2 .-1 \leq \operatorname{SDSQS}_{j} \leq 1$.

Proof: From equation (4) when value of $i$ decreases, then the weight $[n-(i-1)]$ increases, and $\sum_{i=1}^{k} p_{i j}^{E}=1$ and $\sum_{i=1}^{k} p_{i j}^{p}=1$. Hence,

when

$p_{1 j}^{E}=1, p_{\mathrm{ij}}^{\mathrm{E}}=0, i=2,3, \cdots, k ; \quad$ and $\quad p_{i j}^{P}=0, \quad i=1,2, \ldots, k-1 ; p_{k j}^{P}=1$,

then $\operatorname{SDSQS}_{j}=\frac{1}{k-1}(k \times 1+1 \times[-1])=1$, there lies its maximum value. When

$p_{i j}^{E}=0, i=1,2, \ldots, k-1 ; p_{k j}^{E}=1, \quad$ and $\quad p_{1 j}^{P}=1 ; p_{i j}^{P}=0, i=2,3, \ldots, k$; then $\operatorname{SDSQS}_{j}=\frac{1}{k-1}(k \times 1+1 \times[-1])=-1$, it is the minimum value. All other possible values are between -1 and 1 . This completes the proof.

From the discussions above, $S_{D S Q S}{ }_{j}$ can be used as a standardized index to measure the service quality of attributes, and by which the service quality of attribute $j$ is defined as "high" if $\operatorname{SDSQS}{ }_{j}>0$, the closer the $\operatorname{SDSQS}{ }_{j}$ to 1 , the higher the service quality of attribute $j$; the service quality of attribute $j$ is defined as "at-average" if $S D S Q S{ }_{j}=0$; and the service quality of attribute $j$ is defined as "low" if $S D S Q S_{j}<0$, the closer the $S D S Q S_{j}$ to -1 , the lower the service quality of attribute $j$. In the meantime, because $p_{i j}^{E}$ and $p_{i j}^{P}$ can be expressed in the means of two indicator random variables, another advantage of $\operatorname{SDSQS}_{j}$ being a measure of the service quality is that the statistical property of $S D S Q S_{j}$ can be easily evaluated by the Central Limit Theorem (Casella and Berger 2002).

It is easy to verify that $\sum_{i=1}^{k}\left[F_{j}(i)-F_{l}(i)\right]$ has the transitivity property. Therefore, the criterion can be applied to the other specification of service quality. For example, if the performance-based measure of service quality (Cronin and Taylor [11, 12]) is used, the values $\sum_{i=1}^{k}\left[F_{j}(i)-F_{l}(i)\right]$ of the attributes can be obtained from the comparison among the distributions of the attributes' performance ratings each other. After that, those values of $\sum_{i=1}^{k}\left[F_{j}(i)-F_{l}(i)\right]$ could be standardized to the closed interval $\{-1,1]$ and then standardized values are scored to the respective SQ lines on a SQPM to complete the SQRM.

In fact, SDC criterion can be altered as:

$$
\sum_{i=1}^{q}\left[F_{j}^{E}(i)-F_{j}^{P}(i)\right] \geq 0, \quad \forall q=g, g+1, \ldots, k,
$$

with strict inequality for some $j$. This means that scale 1 to scale $g$ in survey data are combined together with same weight. Criterion (7) can be written in the GSQS form as:

$$
\operatorname{GSQS}_{j}=\sum_{i=1}^{q}[k-(g-1)]\left(p_{i j}^{E}-p_{i j}^{P}\right) \geq 0, q=g, g+1, \ldots, k,
$$

with strict inequality for some $q$.

Combining criterion (7) (or (8)) with SDSQS, the two-stage service quality score (TSQS) of attribute $j$ can be defined as: $\mathrm{TSQS}_{\mathrm{j}}=0$, if the criterion (7) does not be satisfied; otherwise 


$$
\operatorname{TSQS}_{j}=\frac{1}{k-1} \sum_{i=1}^{k}\left[F_{j}^{E}(i)-F_{j}^{P}(i)\right]
$$

When $g=1$ criterion (7) is equivalent to SDC; on the other hand, when $g=k$ criterion (7) is equivalent to $S D S Q S$; that is, TSQS is in the middle of SDC and SDSQS. Decision makers can adjust $g$ in accordance to their risk attitudes; therefore TSQS provides a flexible criterion which can be applied by those decision makers with risk attitude in a wide range. Note that TSQS is still a standard index; hence, TSQS can be used for scoring the extent of service quality delivered by the attributes on the SQRM. Because $\mathrm{TSQS}_{j}=0$ when criterion (7) is not satisfied, it will appear many zero scores on the SQRM when $g \neq k$. This means that the final profile of service quality measured by TSQS will be more robust than that of measured by $S D S Q S$.

Instead of using criterion (7) to avoid the issue of the extreme data as the group 3 illustrated in Table 3, the truncated technique can also be considered. That truncating the last percentages, for example $5 \%$, of both customers' expectations and perceptions survey data, the remaining data sets, then are compared by SDC is an alternative to replace the criterion (7). The decision makers can make their choices between these two methods after scrutinizing the structures of survey data.

\section{DISCUSSIONS AND MANAGERIAL IMPLICATIONS}

In this paper we have investigated three questions:

1. How could an alternative technique be constructed that can improve on the insufficiency of IPM, PEM, or SQPZ to convey the overall picture of complex service quality to the managers?

2. Instead of using gap model proposed by Parasuraman et al. $[33,34]$, how could an alternative approach be specified to measure the service quality of the attributes? and

3. How could an alternative index be designed to represent the extent of the service quality delivered by an attribute? And how could the problem of summarizing customers service quality ratings be avoided?

This paper solves the first problem by designing a graphical method which synthesizes various relevant information of service quality into a graph SQRM. The SQRM converts an abstruse and abstract construct of the service quality delivered by the companies to a single graph comprehended easily by executives, managers or other persons who will make decisions based on their research of service quality. The superiority of SQRM to IPM, PEM or SQPZ can improve the technique of presentation of complex information into a simple and single picture practically.

In answer to the last two questions, the literature review suggests that the expectation standard and 'minus' operation cause the problem of P-E specification of service quality and that the skewness of survey distributions raises the inadequacy of commonly used indexes to report the results. Thus, the GSQS made from the weighted average of the differences between relative frequencies of customers' expectation and perceived performance can avoid these problems, thus meet the objectives of this study. As a special case of GSQS, SDSQS is standardized between -1 and 1 , whose concept comes from SDC. Combining SDC with SDSQS, TSQS is proposed.

An examination of the measurement work in industry suggests that the distinction between service quality and customers satisfaction is often ignored in practice (Naumann and Giel [27]; Zeithaml, et al. [48]). However, studies have suggested that service quality and customer satisfaction are distinct constructs (Oliver [31]; Taylor and Baker [44]) and that there is a causal relationship between the two (Cronin and Taylor [11, 12]; Gotlieb, et al. [15]; Spreng and Mackoy [43]). There have also been discussions of the relationship between service quality and customer satisfaction made in the point of transaction-specific and overall attitude (Parasuraman, et al. [36]; Teas [45]). In order to avoid the confusion, this paper uses only the words "service quality", and with prudence. After discussing TSQS and $S Q$ profile, we are trying to define service quality and service satisfaction as follows.

Service quality is the attitude held by customers who have been served by the company at a specific time, and can be distinct from service quality of a specific attribute, service quality of a specific dimension or service quality of a company.

Service quality of a specific attribute is defined as the customers' attitudes towards this specific attribute at a specific time. TSQS $S_{j}$ is taken as the standard measure of service quality of a specific attribute $j$. The extent to which customers are satisfied with this particular service attribute is calculated by $\mathrm{TSQS}_{\mathrm{j}} \times 100 \%$. Because $-1 \leq \mathrm{TSQS}_{\mathrm{j}} \leq 1$, when $\mathrm{TSQS}_{\mathrm{j}}$ is greater than 0 , then service quality of attribute $j$ is said to be good and the extent to which customers are satisfied with this particular service attribute is high, the closer the $\mathrm{TSQS}_{\mathrm{j}}$ to 1 , the better the service quality of the attribute and the higher the extent to which customers are satisfied with this particular service attribute. When TSQS $\mathrm{S}_{\mathrm{j}}$ is equal to 1 , the service quality of the attribute is the best and the extent to which customers are satisfied with this particular service attribute is $100 \%$ However, if TSQS $\mathrm{T}_{\mathrm{j}}$ equals 0 , that indicates the service quality of this attribute is merely "at-average" and the extent to which customers are satisfied with this particular service attribute is $0 \%$. If the $\mathrm{TSQS}_{\mathrm{j}}$ is smaller than 0 , the service quality of attribute $j$ is poor and the extent to which customers are satisfied with this particular service attribute is low. The closer the value to -1 , the worse the service quality of this attribute and the lower the extent to which customers are satisfied with this particular service attribute. When $\mathrm{TSQS}_{\mathrm{j}}$ is equal to -1 , the service quality of the attribute is the worst and the extent to which customers are satisfied with this particular service attribute is $-100 \%$.

Service quality of a specific service dimension is defined as the attitude of the customers' perceptions towards the specific service dimension according to their past experience of uses at a specific time. Its index is defined as :

Index of service quality of a dimension

of the service quality $=\sqrt{\frac{C}{D}}-1$ 
Where

$\mathrm{C}=$ the intersection of the area surrounded by the SQ profile (constructed by survey data) and the sector area of this particular dimension within the circle with a radius of 2 ;

$\mathrm{D}=$ the sector area of this particular dimension within the circle with a radius of 1 ;

The extent to which customers are satisfied with a service dimension

$=$ Index of service quality of this specific service dimension $\times 100 \%$;

The service quality of a specific company is defined as the attitude of customers' perceptions towards the service attributes of this company as a whole at a specific time. The index of service quality of a company is defined as follows:

$$
\begin{aligned}
& \text { Index of service quality of } \\
& \text { a specific company }=\sqrt{\frac{T A}{\pi}}-1
\end{aligned}
$$

where $T A=$ the area of the SQ profile;

The extent to which customers are satisfied with the service delivered by a specific company $=$

Index of service quality of this specific company $\times 100 \%$

By the definitions of (8) and (9), both index of service quality of a dimension of the service quality and index of service quality of a specific company are standardized and within the interval $(-1,1)$. For instance, suppose that all $\mathrm{TSQS}_{\mathrm{j}} \mathrm{s}$ of the attributes within a particular dimension are $1 \mathrm{~s}$, then, in this case $\mathrm{C}$ is approximately equal to the sector area of this particular dimension within the circle with a radius of 2 , and again is approximately equal to $4 \times$ the sector area of this particular dimension within the circle with a radius of 1 . This implied that the index of service quality of this particular dimension of the service quality is approximately equal to 1 , and the extent to which customers are satisfied with this particular service dimension is almost $100 \%$. To see the other extreme case, suppose that all TSQS $\mathrm{T}_{\mathrm{j}}$ of the attributes within this particular dimension are $-1 \mathrm{~s}$, then $\mathrm{C}=0$ because the area of the SQ profile only contains the center point, and the extent to which customers are satisfied with this particular service dimension is $-100 \%$.

In between, suppose that all $\mathrm{TSQS}_{\mathrm{j}} \mathrm{s}$ of the attributes within this particular dimension are $0 \mathrm{~s}$, then $\mathrm{C}$ is approximately equal to the sector area of this particular dimension within the circle with a radius of 1 . In this case, the index of service quality of this particular dimension of the service quality is approximately equal to 0 , and the extent to which customers are satisfied with this particular service dimension is $0 \%$.

In other words, a service quality index with respect to each factor can be computed in the way of equation (8) for each company. The service quality index will give an indication of the service quality delivered by a company (from the customers' viewpoint) with respect to a particular factor. The indices for all the factors of service quality delivered by a company can be computed in this way; therefore, managers can keep these indices as a yardstick, on which improvement efforts can be focused. These indices would also help researchers to better comprehend the different facets of customer-- perceived service quality. Similarly, the index that can be computed by equation (9) for a company will give an indication of service quality delivered by this company. The index can help managers to compare the overall picture of the level of service quality delivered by this company to the service quality delivered the other companies.

\section{IMPLICATIONS FOR FURTHER RESEARCH}

As already discussed, in addition to SERVQUAL P-E specification is still an issue in the research on service quality. TSQS measures the scores of service quality in a way different from SERVQUAL P-E specification. Could TSQS be a measure of service quality better than the P-E specification or the performance-based specification? Would the SQRM with TSQS which try to convey more information about the overall service quality delivered by a company be an appropriate method recognized by the marketing researchers and practitioners? Examination of the relationship between SQ profile and customers' satisfactions under the control of product price and product satisfaction will help the academic community to understand the relationship between service quality and customers' satisfactions, and then to explore the relationship between service quality and purchasing behavior. Pursuing such a research avenue would be advancing the understanding of the characteristics of TSQS and SQRM as well as the service quality. Those studies, in addition to the exploration of academic theories, will help practitioners to draft the strategies of marketing competition in practice.

\section{CONCLUSIONS AND LIMITATION}

In this paper, SQRM is proposed in order to improve the presentation of various complicated information of service quality pertaining to individual attribute, dimensions of attributes and attributes as a whole delivered by companies or markets. The advantages of easy comprehension and comparison of SQRM will make this technique more informative than these methods currently used such as IPM, SEM and SQPZ. We believe that SQRM can better help companies when they want to examine the market position derived from services they provide and when they attempt to make service improvement decisions. We believe that the functions mentioned above, as Zeithaml, et al. ([49], p.153) wished that data gathered through a SERVQUAL survey could spawn, will make a contribution in the exhibition of service quality information academically and practically.

In addition to the requirement of a standardized service quality score by the SQRM, this paper also addresses the problems resulted from taking $\mathrm{P}-\mathrm{E}$ in the approach of SERVQUAL and from summarizing the skewed distributions of attributes rating. This paper then proposes the GSQS method that provides a different approach from SERVQUAL approach in dealing with the difference between expectations and perceived performances to measure the service quality. Instead of using P-E, GSQS targets the difference between the 
relative frequencies of expectations and perceptions, and thus avoids the problem that could happen in P-E specification.

As a special case of GSQS, SDSQS is a standardized service quality index whose values are standardized between interval -1 and 1. Combining SDC and SDSQS, TSQS is proposed. TSQS is between SDC and SDSQS and hence is more flexible than SDC and SDSQS. And TSQS can add the weight of decision makers' risk-preference onto every different scale; therefore, the resulted scores of service quality measured by TSQS are more appropriate to be used in marketing management. TSQS criterion can be applied to the other specification of service quality, such as performance-based specification and others. Based on the TSQS, definition of service quality of a specific attribute, definition of service quality of a specific dimension and definition of service quality of a company are proposed distinctively. The measures of the extent of customers' satisfactions towards these service qualities are also designed.

In order to include all service attributes and dimensions on a single graph, SQRM is designed to manifest those dimensions whose eigenvalues are significant and those attributes whose factor loadings are also significant on their respective dimensions. When both dimensions and attributes included in those dimensions are numerous, the alternative to include those attributes chosen by surrogate variable method such as one-per-factor may be considered (Hair et al. 1998). Furthermore, if the risk attitude of decision makers is more conservative, then it will be better for the company to estimate a set of relevant weights and $g$ in TSQS to measure the service quality delivered by a particular company.

\section{REFERENCES}

1. Babakus, E. and Boller, G. W., "An empirical assessment of the SERVQUAL scale,” Journal of Business Research, Vol. 24, pp. 253-68 (1992).

2. Babakus, E. and Mangold, W. G.., "Adapting the SERVQUAL Scale to hospital service: an empirical investigation," Health Service Research, Vol. 26, No. 6, pp. 767-80 (1992).

3. Bawa, V. J., "Optimal rules for ordering uncertain prospects," Journal of Financial Economics, pp. 95-121 (1975).

4. Berry, L. L., Parasuraman, A. and Zeithaml, V. A., "Ten lessons for improving service quality," Marketing Science Institute Working Paper, Report No. 93-104 (1993).

5. Bollun, K. A. and Lennox, R., "Conventional wisdom on measurement: a structural equation perspective," Psychological Bulletin, Vol. 110, pp. 305-14 (1991).

6. Brady, M. K., Cronin, J. J. and Brand, R. R., "Performance-only measurement of service quality: a replication and extension," Journal of Business Research, Vol. 55, No. 1, pp. 17-31 (2002).

7. Brown, Tom J., Churchill, Jr., G. A. and Peter, J. P., "Improving the measurement of service quality," A.C. Nielsen working paper, No. 91-4, University of Wisconsin Madison, Madison, WI (1992).

8. Caruana, A., Michael, T. E. and Ramaseshan, B., "Assessment of the three-column format SERVQUAL: an experimental approach," Journal of Business Research, Vol. 49, No. 1, pp. 57-65 (2000).

9. Casella, G. and Berger, R. L., Statistical Inference, 2nd, CA: Duxbury (2002).

10. Chen, F. Y. and Chang, Y. H., "Examining airline service quality from a process prospective," Journal of Air Transport Management, Vol. 11, pp. 79-87 (2005).

11. Cronin, J. J. Jr., and Taylor, S. A., "Measuring service quality: a reexamination and extension," Journal of Marketing, Vol. 56, No.3, pp. 55-68 (1992).
12. Cronin, J. J. Jr., and Taylor, S. A., "SERVPERF versus SERVQUAL: reconciling performance-based and perceptions-minus-expectations measurement of service quality," Journal of Marketing, Vol. 58, pp. 125-131 (1994).

13. Durvasula, S., Lysonski, S. and Mehta, S. C., "Testing the SERVQUAL scale in the business-to-business sector: the case of ocean freight shipping service," The Journal of Services Marketing, Vol. 13, No. 2, pp. 132-150 (1999).

14. Estelami, H. and and DeMaeyer, P. R., "A visual approach for identifying customer satisfaction segment," Journal of Consumer Satisfaction Dissatisfaction, and Complaining Behavior, Vol. 10, pp. 104-15 (1997).

15. Gotlieb, J. B., Grewal, D. and Brown, S. W., "Consumer satisfaction and perceived quality: complementary or divergent constructs?" Journal of Applied Psychology, Vol. 79, pp. 875-885 (1994).

16. Hair, Jr. J. F., Anderson, R. E., Tatham, R. L. and Black, W. C., Multivariate Data Analysis, 5th ed., Prentice-Hall, N. J. (1998).

17. Hung, Y. H., Huang, M. L. and Chen, K. S., "Service quality evaluation by service quality performance matrix," Total Quality Management and Business Excellence, Vol. 14, No. 1, pp.79-89 (2003).

18. Hurley, R. F. and Estelami, H., “Alternative Indexes for Monitoring Customer Perceptions of Service Quality: A Comparative Evaluation in a Retail Context," Journal of the Academy of Marketing Science, Vol. 26, No. 3, pp. 209-21 (1998).

19. Kira, D., and Ziemba, W. T., "Equivalence among alternatives portfolio selection," in: Levy and Sarnet (eds), Financial Decision Making Under Uncertainty, pp. 151-161, Academic Press, New York (1977).

20. Laffont, J. J., The Economics of Uncertainty and Information, Cambridge, MA: MIT Press (1989).

21. Lambert, D. M. and Sharma, A., "A customer-based competitive analysis for logistics decisions," International Journal of Physical Distribution and Logistics Management, Vol. 20, No. 1, pp. 17-24 (1990).

22. Lambert, D. M. and Stock, J. R., Strategic Logistics Management, Irwin (1999).

23. Levy, H. and Kroll, Y., "Stochastic dominance with riskless assets," Journal of Financial and Quantitative Analysis, pp. 743-778 (1976).

24. Llosa, S., Chandon, J. L. and Orsingher, C., "An empirical study of SERVQUAL's dimensionality," The Service Industries Journal, Vol. 18 , No. 2, pp. 16-44 (1998).

25. Martilla, J. A. and James, J. C., "Importance-performance analysis," Journal of Marketing, Vol. 41, No. 1, pp. 77-79 (1977).

26. Martin, D. W., “An importance-performance analysis of service providers' perception of quality service in hotel industry," Journal of Hospitality and Leisure Marketing 3, pp. 5-17 (1995).

27. Naumman, E. and Giel, K., Customer Satisfaction Measurement and Management, Cincinnati, OH: Thomson Executive Press (1995).

28. Oliver, R. L., "A cognitive model of the antecedents and consequences of satisfaction decisions," Journal of Marketing Research, Vol. 17, pp. 46-69 (1980).

29. Oliver, R. L., "Measurement and evaluation of satisfaction processes in retail settings," Journal of Retailing, Vol. 57, pp. 25-48 (1981).

30. Oliver, R. L., "A conceptual model of service quality and service satisfaction: compatible goals, Different Concepts," in: Advances in Service Marketing and Management: Research and Practice, Vol. 2, Swartz, T. A., Bowen, D. E., and Brown, S. W., (eds), Greenwich, CT: JAI Press (1993).

31. Oliver, R. L., Satisfaction: A Behavioral Perspective on the Consumer, New York: McGraw-Hill (1997).

32. Parasuraman, A., Berry, L. L. and Zeithaml, V. A., "Refinement and reassessment of the SERVQUAL scale," Journal of Retailing, Vol. 67, pp. 42-50 (1991).

33. Parasuraman, A., Zeithaml, V. A. and Berry, L. L., "A conceptual model of service quality and its implications for further research," Journal of Marketing, Vol. 49, pp. 41-50 (1985).

34. Parasuraman, A., Zeithaml, V. A. and Berry, L. L., "SERVQUAL: a multiple-item scale for measuring consumer perceptions of service quality," Journal of Retailing, Vol. 64, No. 1, pp. 12-40 (1988).

35. Parasuraman, A., Zeithaml, V. A. and Berry, L. L., "Alternative scales for measuring service quality: a comparative assessment based on psychometric and diagnostic criteria," Journal of Retailing, Vol. 70, No. 3, pp. 201-30 (1994a).

36. Parasuraman, A., Zeithaml, V. A. and Berry, L. L., "Reassessment of 
expectation as a comparison standard in measuring service quality: implications for further research," Journal of Marketing, Vol. 58, pp. 11-24 (1994b).

37. Peter, J. P., Churchill, Jr., G. A. and Brown, T. J., "Caution in the use of difference scores as measures of marketing constructs," A. C. Nielsen Working Paper, No.91-2, University of Wisconsin-Madison, Madison, WI (1992).

38. Peterson, R. A. and Wilson, W. R., "Measuring customer satisfaction: fact and artifact," Journal of the Academy of Marketing Science, Vol. 20, pp. 61-71 (1992).

39. Port, R. B., Wart, J. R. and Furguson, D. L., "Efficient algorithms foe conducting stochastic dominance tests of large numbers of portfolios," Journal of Financial and Quantitative Analysis, pp. 71-82 (1973).

40. Rosen, L. D., Karwan, K. R. and Scribner, L. L., "Service quality measurement and the disconfirmation model: Taking care in interpretation," Total Quality Management \& Business Excellence, Vol. 14, No. 1, pp. 3-14 (2003).

41. Rothschild, M., and Stiglitz, J. E., "Increasing risk: I. A definition," Journal of Economic Theory, Vol. 2, pp. 225-243 (1970).

42. Sivadas, E., "Europeans have a different take on customer programs," Marketing News, p.39 (1998).

43. Spreng, R. A. and Mackoy, R. D., "An empirical examination of a model of perceived service quality and satisfaction," Journal of Retailing, Vol.
72, pp. 201-214 (1996).

44. Taylor, S. A. and Baker, T. L., "An assessment of the eelationship between service quality and customer satisfaction in the formation of consumer's purchase intentions," Journal of Retailing, Vol. 70, No. 2, pp. 163-178 (1994).

45. Teas, R. K., "Expectations, performance evaluation and consumers' perceptions of quality," Journal of Marketing, Vol. 57, pp. 204-12 (1993).

46. Vickson, R. G. and Altman, M., "On the relative effectiveness of stochastic dominance rules: extension to decreasingly risk-averse utility functions," Journal of Financial and Quantitative Analysis, pp. 73-84 (1977).

47. Whitmore, G. A., "Third degree stochastic dominance," American Economic Review, pp. 457-459 (1970).

48. Zeithaml, V. A., Parasuraman, A., and Berry, L. L., "The behavioral consequences of service quality," Journal of Marketing, Vol. 60, pp. 31-46 (1996).

49. Zeithaml, V. A., Bitner, M. J. and Gremler, D. D., Services Marketing, 4th ed., NY: McGraw-Hill (2006).

50. Zhang, H. Q., and Chow, I., "Application of importance-performance model in tour guides' performance: evidence from mainland Chinese outbound visitors in Hong Kong," Tourism Management, Vol. 25, pp. 81-91 (2004). 